\title{
Standardization of A375 human melanoma models on chicken embryo chorioallantoic membrane and Balb/c nude mice
}

\author{
STEFANA AVRAM $^{1 *}$, DORINA-ELENA CORICOVAC ${ }^{2 *}$, IOANA ZINUCA PAVEL $^{1}$, \\ IULIA PINZARU ${ }^{2}$, ROXANA GHIULAI $^{3}$, FLAVIA BADERCA ${ }^{4}$, CODRUTA SOICA $^{3}$, \\ DANINA MUNTEAN ${ }^{5}$, DACIANA E. BRANISTEANU ${ }^{6}$, DEMETRIOS A. SPANDIDOS ${ }^{7}$, \\ ARISTIDES M. TSATSAKIS ${ }^{8}$ and CRISTINA ADRIANA DEHELEAN ${ }^{2}$
}

\begin{abstract}
Departments of ${ }^{1}$ Pharmacognosy, ${ }^{2}$ Toxicology and ${ }^{3}$ Pharmaceutical Chemistry, Faculty of Pharmacy, and Departments of ${ }^{4}$ Microscopic Morphology and ${ }^{5}$ Pathophysiology, Faculty of Medicine, 'Victor Babeș’ University of Medicine and Pharmacy Timisoara, Timisoara 300041; ${ }^{6}$ Department of Dermatology and Venereology, 'Grigore T. Popa'

University of Medicine and Pharmacy Iasi, Iasi 7000115, Romania; ${ }^{7}$ Laboratory of Clinical Virology,

School of Medicine, University of Crete; ${ }^{8}$ Department of Forensic Sciences and Toxicology, Faculty of Medicine, University of Crete, Heraklion 71003, Greece
\end{abstract}

Received February 6, 2017; Accepted May 8, 2017

DOI: $10.3892 / o r .2017 .5658$

\begin{abstract}
Cutaneous melanoma is a metastatic disease characterized by high resistance to treatment, the incidence of which has alarmingly increased worldwide over the past years. A thorough characterization of tumor onset, progression and metastasis is compulsory to overcome the gaps existent in melanomabiology. The present study suggests a well-established protocol and a detailed histological description of human melanoma models in ovo and in vivo obtained by the inoculation of A375 cells to chick embryo chorioallantoic membrane (CAM) and $\mathrm{Balb} / \mathrm{c}$ nude mice. The inoculation of A375 cells on CAM led to the formation of compact primary and secondary tumors on day 4 post-inoculation, with mean surface area values of $2.2 \pm 0.4 \mathrm{~mm}^{2}$ and $1.5 \pm 0.3 \mathrm{~mm}^{2}$, respectively. Moreover, the vessels around the tumors presented a spike wheel pattern, indicating a strong angiogenic reaction. All the injected mice, apart from one, developed solid polypoid primary tumors with lobulated surfaces and intense vascularization, and achromic epithelioid malignant melanocytes with vesiculous nuclei and necrosis area were detected. Metastasis was histologically confirmed in only $30 \%$ of the mice with the tumor xenografts. These data indicate that the standardization protocols proposed are complex and reproducible, and can be further employed for
\end{abstract}

Correspondence to: Dr Flavia Baderca, Department of Microscopic Morphology, Faculty of Medicine, 'Victor Babeș' University of Medicine and Pharmacy Timisoara, 2 Eftimie Murgu Sq, Timisoara 300041, Romania

E-mail: flaviabaderca@gmail.com

*Contributed equally

Key words: melanoma, chick embryo chorioallantoic membrane assay, A375 cell line, Balb/c nude mice, metastasis, angiogenesis the therapeutic surveillance of antiangiogenic and anticancer agents.

\section{Introduction}

Melanoma is described as a malignant tumor that originates from melanocytes, the melanin-producing cells. The tumors can be diagnosed on the skin, ocular membranes, retroperitoneal space, parenchymatous organs and different mucosa (1-3); however, $95 \%$ of all melanoma cases are located on the skin (4). Even if these tumors originate from the same cell, melanomas should be considered as a family of diseases instead of a single tumor, with a different etiology, pathogenesis, behavior and evolution, depending on the site of occurrence.

The genetic signature of melanomas comprises different profiles of somatic mutations engaged in tumorigenesis (5), and also multiple risk factors, including environmental, genetic and phenotypic factors (6), features that convert this pathology into an aggressive and a disorder with a poor prognosis; melanoma is considered one of the most lethal types of cancer, accounting for $75 \%$ of skin cancer-related mortalities (4). The high rate of mortality, which is characteristic of this aggressive disease is associated with a heterogeneous molecular pattern caused by multiple progressive mutations. The recent advances in the molecular therapy of mutant melanoma are considerable; however, this type of therapy is still confronted with secondary effects and is resistant to treatment (7-9). Despite considerable progress in the understanding of the mechanisms responsible for melanoma development and progression, mechanistic insights and in the discovery of alternative therapeutic approaches (10), the approved anti-melanoma agents have failed to enhance the survival rate of patients with melanoma, and there are still some gaps to fill concerning melanoma biology (11).

The resolution for the aforementioned issues can be achieved by using in vivo models that recreate the exact biological features of melanoma. 
An alternative in vivo experimental model suitable for cancer studies is the chick embryo chorioallantoic membrane (CAM) assay (12), due to its capillary plexus characteristics, and to the fact that it is considered favorable to tumor grafting, enabling neovascularization and invasiveness. Hence the assay is applied in order to investigate the multiple steps of tumor progression, metastatic behavior and molecular deregulated pathways for a large number of cancer types, including sarcoma, lymphoma, ovarian cancer, breast cancer, hepatocellular carcinoma and melanoma (13-18).

Another important tool for understanding the fundamental molecular mechanisms involved in the development of cancer, in general, and melanoma in particular, and to ascertain new or improved procedures for the prevention, diagnosis and treatment of cancer is considered to be the use of animal models (19). Mouse models are by far the most widely employed animal models for melanoma studies due to the extensive genetic knowledge available at present, and due to their easy manipulation and availability $(3,20)$. These models provide important data about the function of specific proteins in melanoma progression. Moreover, these types of assays play a major role in the evaluation of novel anticancer agents (21).

The A375 cell line is derived from a skin primary melanoma of a 54-year-old female and has an epithelioid morphology carrying two mutant genes, $B-R A F$ and $C D K N 2$. Both mutations are associated with melanoma of sun-damaged skin (6).

The present study was carried out with the aim: i) to present a well-established protocol that includes the steps for obtaining in vivo xenograft models of human melanoma using the A375 cell line on two hosts, namely CAM and immunocompromised Balb/c nude mice; ii) to offer a complete macroscopic and histological characterization; and iii) to highlight the inconveniences associated with model development.

\section{Materials and methods}

Cell lines. The A375 achromic human melanoma cells were obtained from ECACC (European Collection of Cell Cultures, Wiltshire, UK). In order to obtain the xenografts, the A375 cells were cultured in Dulbecco's modified Eagle's medium (DMEM) with high glucose (4.5 g/l), L-glutamine and sodium bicarbonate, supplemented with $100 \mathrm{U} / \mathrm{ml}$ penicillin, $100 \mu \mathrm{g} / \mathrm{ml}$ streptomycin and $10 \%$ fetal calf serum (FCS). The cells were kept in a humidified atmosphere with $5 \% \mathrm{CO}_{2}$ at $37^{\circ} \mathrm{C}$ and were passaged every 2 days. The culture media and all the other supplements and reagents required for cell culture were purchased from Sigma-Aldrich Chemie GmbH (Steinheim, Germany).

CAM model of A375 human melanoma. Fertilized eggs were horizontally incubated, 7 days prior to use, at $37^{\circ} \mathrm{C}$, in a controlled wet atmosphere. On the 3 rd day of incubation, $3 \mathrm{ml}$ of albumen were aspired through a perforation at the more pointed end of the eggs, in order to detach the chorioallantoic membrane from the inner shell. The perforated hole was resealed and the eggs were placed into an incubator. The following day, a window was cut and resealed at the superior side of the shell, as previously described (22).

The A375 achromic human melanoma cell suspension in culture medium $\left(10^{4}\right.$ cells $\left./ 2 \mu \mathrm{l}\right)$ was inoculated inside plastic rings on the 10th embryonic developmental day (EDD; experimental day 0). The control samples were treated with the same volume of culture medium administered inside plastic rings on the same day as the cell grafts. In ovo stereomicroscopic monitoring was performed daily for 7 days in order to register the development and progression of the tumor and metastasis formation, as well as the changes in the vascular response surrounding the tumor area. Significant images were further used for morphometric analysis. On day 8 , the final day of the experiment, after sacrificing the embryos, the chorioallantoic membrane, the formed tumors and metastasis were also analyzed ex ovo and ex vivo, by dissecting the areas of interest of the CAM and observing them in a petri dish under a Zeiss Axio V16 Stereomicroscope, using the Axio CAM digital camera and Zeiss ZEN software (Carl Zeiss, Jena, Germany) to record and process representative images.

Vessel density was evaluated by applying an arbitrary $0-5$ scale that estimates the number of capillaries that are convergent towards the tumor area (12). The same scale was applied for the specimens that were treated with cell medium. The evaluated scores are expressed as mean values \pm standard deviation as follows: 0 indicates an unaltered vascular network comparable to the blank sample; 1 indicates a slight increase in vessel density; while 2, 3, 4 and 5 indicate a progressive increase in the number of capillaries converging to the tumor area. Low values are indicative of a normal degree of vascularization, while high values $(>3)$ correlate with an ongoing angiogenic process. The evaluation was performed on the 4th day after the inoculation of cells, or the cell medium, respectively.

\section{Mouse model of A375 human melanoma}

Animals. Balb/c nude male mice (8 weeks old) were purchased from Charles River Laboratories (Budapest, Hungary) and allowed to acclimatize for 2 weeks prior to the experiment. The standard conditions for animal housing were in agreement with the European Directive 2010/63/EU and the national law 43/2014: a 12-h light/dark cycle, at a normal $\left(20-24^{\circ} \mathrm{C}\right)$ temperature, humidity between $45-65 \%$, food ad libitum with free access to water. The protocol applied respected the $3 \mathrm{R}$ concept (replacement, reduction and refinement) and the number of animals used for tumor development was $n=15$. The control group consisted of 3 healthy mice that were not inoculated with melanoma cells.

All experimental procedures and protocols were in agreement with the European Directive2010/63/EU and the American Veterinary Medical Association (AVMA) Guidelines for the Euthanasia of Animals (2013 Edition) regarding the protection of animals used for scientific purposes. The experiments were approved by the Bioethical Committee of 'Victor Babes' University of Medicine and Pharmacy Timisoara, Romania.

Mouse model experimental design. For the ectopic inoculation, the A375 cells were prepared as follows: the cells were cultured in DMEM, grown until appropriate confluence $(80-90 \%)$, numbered in the presence of trypan blue and re-suspended in phosphate-buffered saline (PBS). Each Balb/c nude male mouse was inoculated subcutaneously with $1 \times 10^{7}$ A375 cells in $100 \mu 1$ PBS (23) into the left flank under isoflurane anesthesia, the degree of pain and distress being reduced at minimum. 
For the macroscopic evaluation of mouse evolution, images were acquired starting with the inoculation day and continued every 3rd day/daily following tumor onset until the end of the experiment. Body weights were recorded every 3rd day. Tumor volume was measured with calipers and was calculated using the formula $\mathrm{V}=0.5 \mathrm{ab}^{2}$, where ' $\mathrm{a}$ ' and ' $\mathrm{b}$ ' are the long and the short diameters of the tumor, respectively, as previously described (23).

Histopathological evaluation. The mice were sacrificed when the tumor reached the parameters that confine mouse pain and distress, as postulated by the Institutional Animal Care and Use Committee (IACUC) Guidelines regarding tumor production in rats and mice: tumor size must not exceed $20 \mathrm{~mm}$ at the largest diameter and a volume of $1,700 \mathrm{~mm}^{3}$. Therefore, the mice were euthanized on days 30,45 and 60 post-inoculation, using isoflurane anesthesia followed by cervical dislocation, a procedure conforming with the AVMA Guidelines. The same procedure was performed when the healthy mice from the control group were euthanized, one mouse at each time point aforementioned.

For histological analysis, samples of the tumor developed at the inoculation site and apparently normal, non-involved surrounding skin, liver, lung, kidney and spleen were harvested. The specimens were fixed in $10 \%$ buffered formalin, processed using a classical histological technique and embedded in paraffin. Four micrometer-thick sections were cut using a Leica Rotary Microtome (Leica Biosystems Nussloch GmbH, Nussloch, Germany) and attached on microscopic slides. For diagnostic purposes, the slides were stained with hematoxylin and eosin (H\&E).

\section{Results}

CAM model of human melanoma. Following the inoculation of A375 achromic human melanoma cells on chick chorioallantoic membrane, a relatively good survival rate of the embryos was recorded, approximately $65 \%$ on day 4 and $50 \%$ on day 8 (data not shown). On the final day of the experiment, sections were dissected representing control CAM areas, those presenting the primary tumors inside the ring, as well as areas with secondary formed tumors, as recorded in the ex vivo images [Fig. 1B (normal CAM), G (primary tumor site) and $\mathrm{H}$ (secondary tumor site)].

On day 2 after inoculation, tumor cells were still scattered inside the ring without forming compact masses, but the onset of tumor establishment was already observed by the 3rd day. On this day, areas of A375 cells were found outside the ring perimeter, indicating their tendency to form secondary tumors. Tumor masses were more compact from the 4th day on the primary site (Fig. 1C), and compact secondary tumor masses were firstly observed at some distance from the ring (Fig. 1D).

By day 7 the areas reached approximately one fifth of the surface inside the ring. On day 8 , the final day of the experiment, tumors and metastases were evaluated $e x$ vivo, and dimensions were estimated as the average surface area of $2.2 \pm 0.4 \mathrm{~mm}^{2}$ for primary tumors (Fig. $1 \mathrm{G}$ ) and $1.5 \pm 0.3 \mathrm{~mm}^{2}$ for secondary tumors (Fig. $1 \mathrm{H}$ ).

From day 4 of the experiment, primary and secondary perfused tumor masses were formed, showing strong angiogenic reactions, with a capillary mesh with a tortuous aspect and some signs of hemorrhagic foci (Fig. 1D and F).
The vascular reaction to the presence of tumor cells was progressively stronger from day 4 to the final stage of the experiment. The number of capillaries converging toward the ring area was significantly higher in the specimens with A375 cells [Fig. 1C (day 4) and E (day 4, right ring), and G (day 8)] as compared with the control treated only with cell medium [Fig. 1A (day 4), B (day 8) and E (left ring)]. The characteristic spoke wheel pattern of vessel arrangement indicates the strong angiogenic reaction noticeable from the 3rd day after cell inoculation and which was prominent on day 4 [Fig. 1E (left ring) and F]. The same type of strong vascular reaction was present around the metastatic sites (Fig. 1D). On day 8, tumors were intensely vascularized and exhibited perfused intratumoral vessels and at the periphery of tumor areas as well, which were confirmed by microscopic evaluation (data not shown).

Vessel density was estimated by applying an arbitrary scale and represents the degree of vascularization convergent towards the tumor area. The average vascular density was significantly higher in areas where tumor masses were present (4.8 \pm 0.2$)$, compared to the control specimens $(3.1 \pm 0.2)$, as presented in Fig. 2 .

\section{Mouse model of A375 human melanoma}

Macroscopic evaluation. The inoculation of melanoma cells was well-tolerated by all animals and no signs of clinical deterioration (significant weight loss, loss of appetite or reduced mobility) were detected post-inoculation. A liquid bubble was formed during inoculation that retracted on the first day post-inoculation (data not shown).

Following the resorption of the inoculation bubble, in 14 mice, the first signs of tumor onset were observed on day 10-12 post-injection, with slight individual differences (Fig. 3A). Only one mouse did not develop a primary tumor at the site of inoculation.

On day 20 post-inoculation, the initial tumors became well-defined, as solid polypoid tumors with a lobulated surface (Fig. 3B). Moreover, by day 30 post-inoculation, the tumor dimensions grew larger and newly formed blood vessels within the primary tumors were prominent (Fig. 3C). No sign of ulceration was observed on the overlying skin during the entire experiment.

The mice inoculated with A375 xenografts presented some weight variations during the experimental period and the values recorded were lower than the ones measured for the control group, the differences not being statistically significant (Fig. 4). Some of the inoculated mice presented a greater weight due to the developed tumor.

The tumor volumes are presented in Fig. 5, calculated to chart the tumor growth curve. It was observed that the tumors presented a linear growth until day 30 post-inoculation, whereas after this time point, the growth became accelerated, and an increase was also detected in tumor volume values (Fig. 5).

Histopathological evaluation of human melanoma mouse model. Due to the tumor size, 3 mice were sacrificed at 30 days post-inoculation, 3 mice at 45 days and the remaining 8 mice at 60 days post-inoculation.

In all 14 cases, nodular tumors composed of islands of achromic epithelioid cells were observed, with a large cytoplasm, vesiculous nuclei and prominent macronucleoli. The 

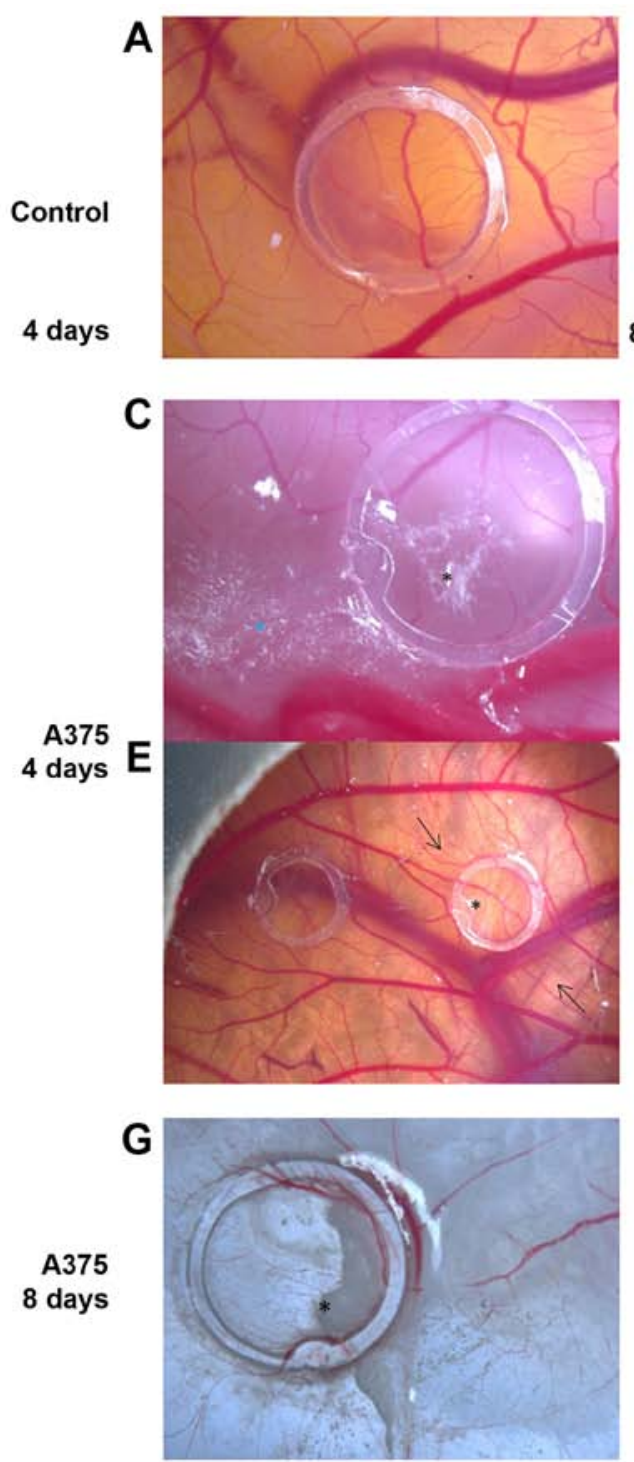

B

8 days
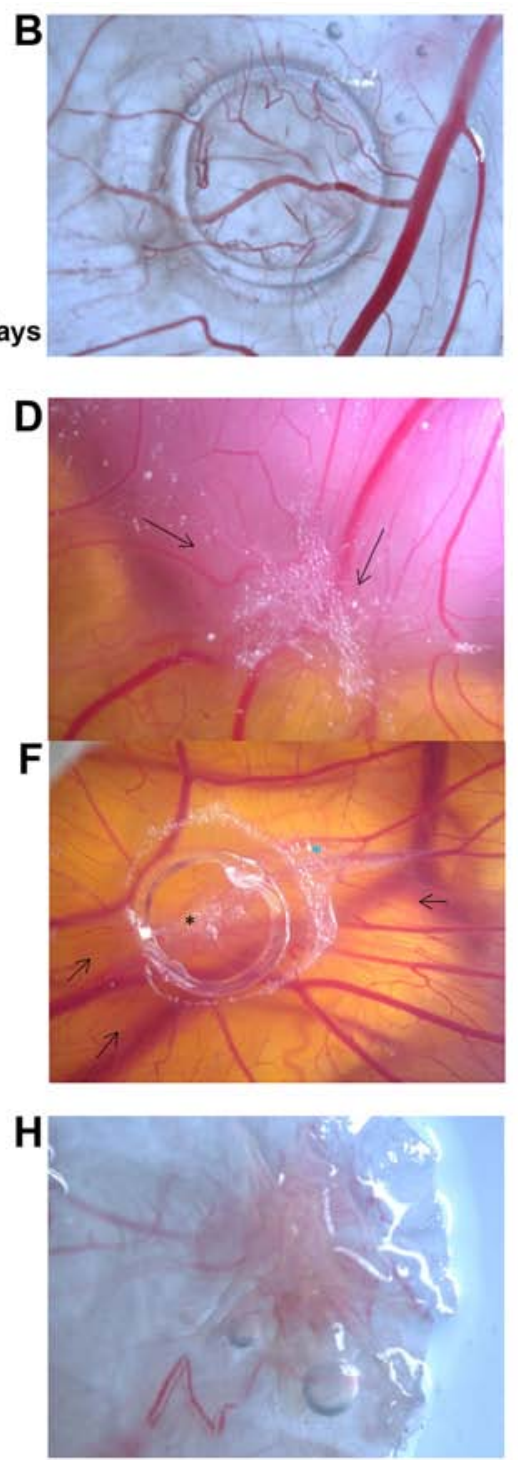

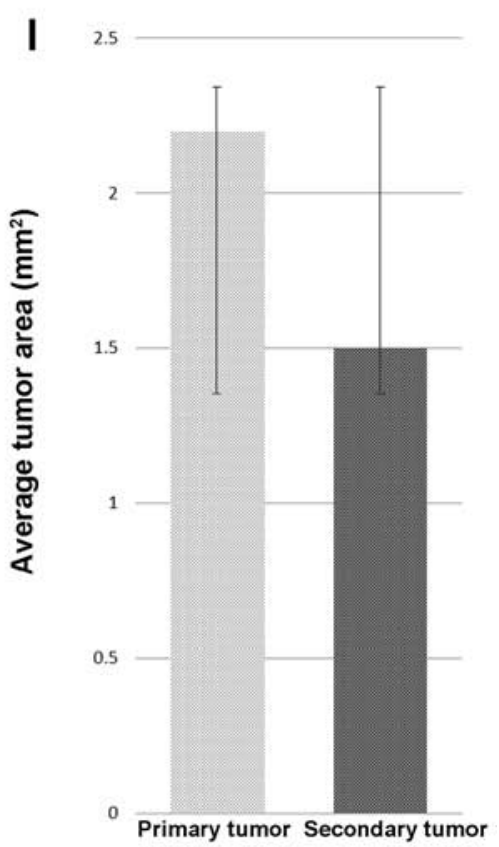

Figure 1. A375 melanoma cell graft and tumor formation on chick embryo chorioallantoic membrane (CAM); stereomicroscopy: control, no tumor formation on day 4 [A, (left ring in E)], and day 8 (B); melanoma xenograft at 4 days after cell inoculation-primary tumor [C (black asterisk), E (right ring) and F], secondary tumor onset [C (blue asterisk) and F) secondary tumor (D); 8 days after inoculation, primary tumor [G (black asterisk)], secondary tumor (H); black arrows indicate high vessel density converging towards the tumors. (I) Average areas of tumors obtained on CAM on day 8 of the experiment: primary tumors were $2.2 \pm 0.4 \mathrm{~mm}^{2}$ and secondary tumors were $1.5 \pm 0.3 \mathrm{~mm}^{2}$.

tumor stroma was represented by few collagen fibers. The tumor occupied the entire dermis and the subcutis, with the grenz zone to the epidermis extended to the subcutis and invading the adjacent striated muscle cells. Large areas of necrosis were noted. The epidermis was not involved, and was not ulcerated by the tumor (Fig. 6). These features were consistent with achromic nodular melanoma.

The volume of the tumor and the areas of necrosis increased from 30 to 60 days (Fig. 6D). Moreover, at 60 days post-inoculation, a number of hyperemiated vessels were identified between the tumor cells (Fig. 6C).

In the skin around the tumor, an increased number of mast cells was observed compared to the group control. Moreover, the number of mast cells increased from the mice sacrificed at 30 days compared to those sacrificed at 60 days. The distribution of mast cells varied between groups. In the control group, few mast cells filled with granules were observed in the super- ficial dermis, while on the 60th day of the experiment, large numbers of mast cells were observed in all levels of the dermis and in the subcutis in the close vicinity of the tumor (Fig. 7).

The ability to develop metastasis was decreased from the first group to the last. At 30 days post-inoculation, one mouse presented lung metastasis (Fig. 8A and B, 30 days) and one spleen metastasis (Fig. 8C, 30 days). In a third mouse sacrificed at that time, no metastasis was observed, only large tumor thrombi in the large-sized arterial blood vessel (Fig. 8D, 30 days). In the second group, only one mouse presented kidney metastasis (Fig. 8, 45 days), while in the third group, the mice developed any metastasis. In this group, the most affected organ in response to the tumor status was the lung, exhibiting hemorrhagic alveolitis with many erythrocytes extravasated in the alveolar space and hyperemia of the large vessels (Fig. 8, 60 days). All the metastases were microscopic. 


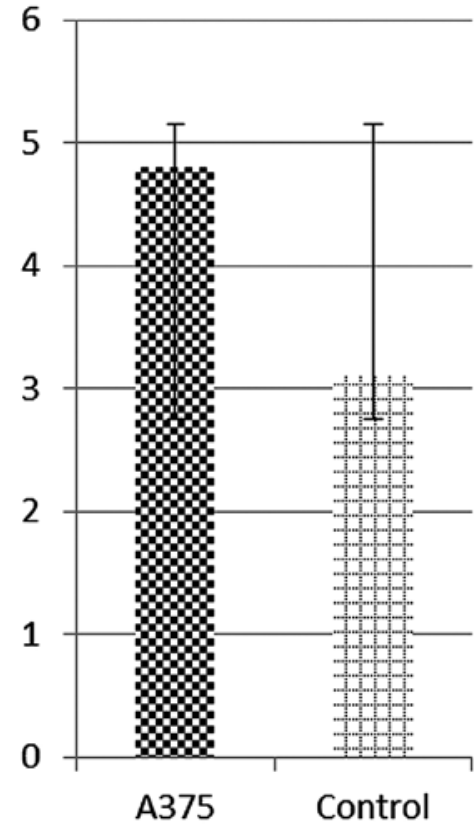

Figure 2. Vascular density around tumor areas on day 4 after the inoculation of A375 melanoma cells, and control cell medium, respectively, as indicated by scores on a $0-5$ scale using the CAM assay.

A
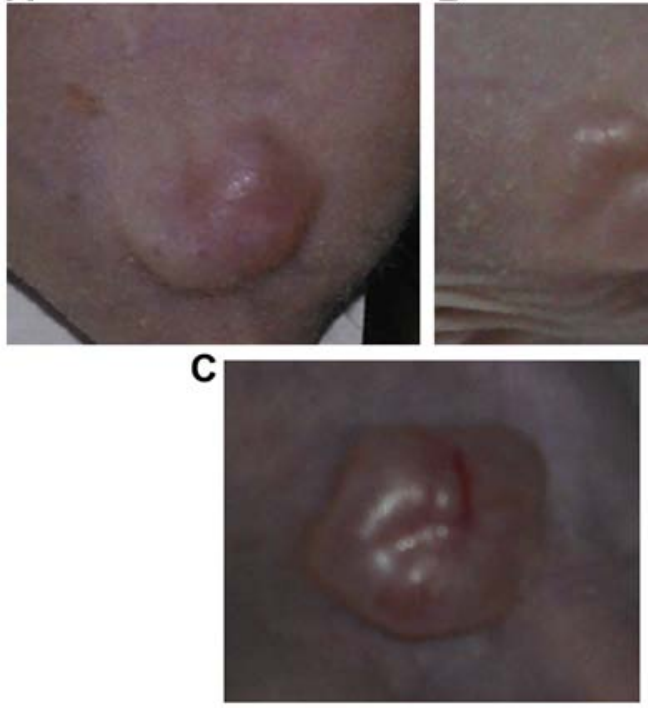

Figure 3. Representative images of tumor development in the A375 xenograft model. (A) Tumor onset at 10 days post-inoculation, (B) a palpable, well-defined tumor at 20 days post-inoculation, and (C) tumor appearance with prominent blood vessels at 30 days post-inoculation.

The other harvested internal organs exhibited only hyperemia of small vessels (Fig. 9), with increasing intensity from the first group to the last (30-60 days).

\section{Discussion}

The incidence of cutaneous melanoma has increased at an alarming rate worldwide over the past years. According to the World Cancer Research Fund International, GLOBOCAN 2012, there were an estimated 230,000 new cases of melanoma worldwide in 2012 (24), and the statistics offered by the WHO

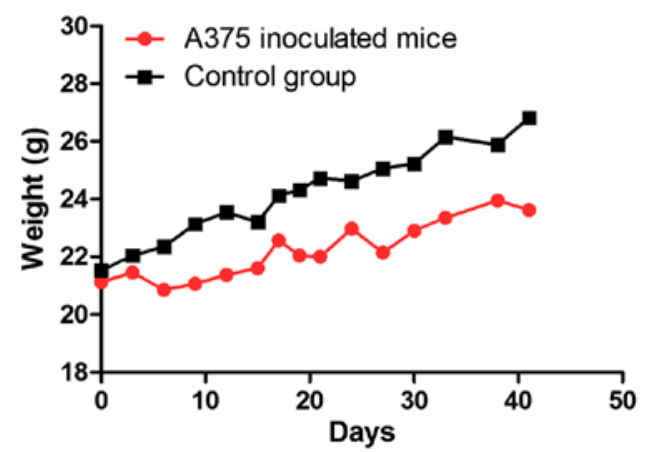

Figure 4. Mouse weight evolution during the experiment. The values are expressed as the mean.

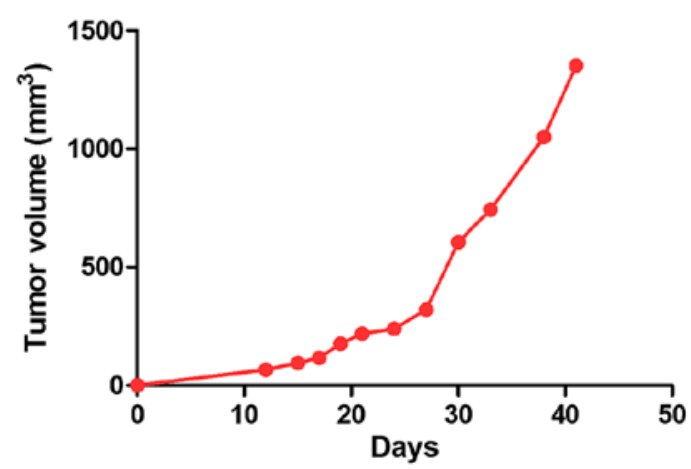

Figure 5. Tumor volume evolution during the experiment. The values are expressed as the mean.

indicate that almost 132,000 cases of melanoma are being diagnosed each year globally (25). On the other hand, the incidence of mucosal and ocular melanomas seems to remain stable worldwide $(1,2,26)$, with some racial and regional differences.

Even if the presence of skin melanoma in Asiatic individuals seems to be uncommon, the oral cavity melanomas are more often diagnosed in Japanese and Ugandan African populations, accounting $35 \%$ of all mucosal melanomas, compared to $3.6 \%$ in caucasions. Even so, a recent study demonstrated a higher prevalence of oral cavity melanomas, accounting $25 \%$ of all mucosal melanomas diagnosed during a period of 10 years, due to the habitual particularity of Romania's population $(1,2)$.

There are also differences between ages at the time of diagnosis. Cutaneous melanomas are diagnosed at a young age, but the extra-cutaneous counterpart seems to be a disease affecting the elderly, with a peak of incidence in the 7th decade of life compared to the 3rd decade for the former. Moreover, the age at the time of diagnosis appears to decrease over the past years of life for skin melanomas (27), a fact that is not been observed for the extra-cutaneous counterpart.

Over the past years, an entire cascade of genetic abnormalities has been identified which is associated with melanoma. Studies have reported that 25 molecules/genes are associated with melanoma biology, namely progression, metastasis and prognosis, such as $C D K N 2 A$ (cell cycle-related gene), $P I 3 K$ and PTEN, $N-R A S$ (15-20\% of all cutaneous melanomas), $B-R A F$ (50\% of all cutaneous melanomas) and MITF (28-30). The $B-R A F$ gene encodes a serine/threonine protein kinase that acts as a regulator of cell division, differentiation and secretion 
A
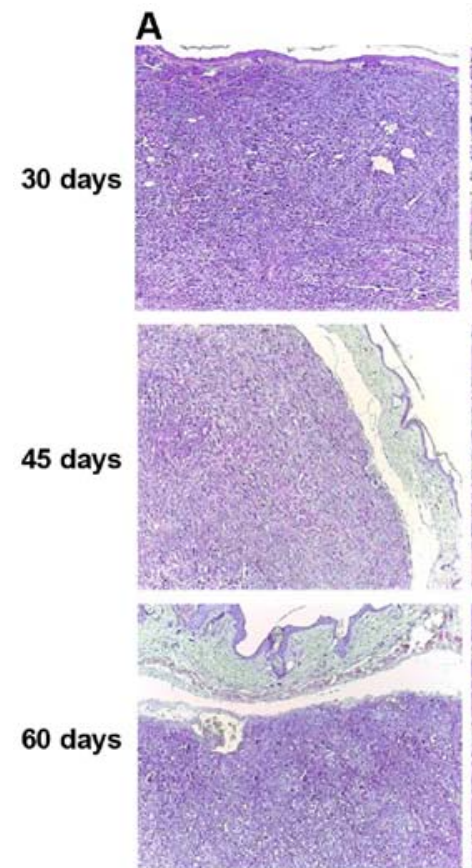

B
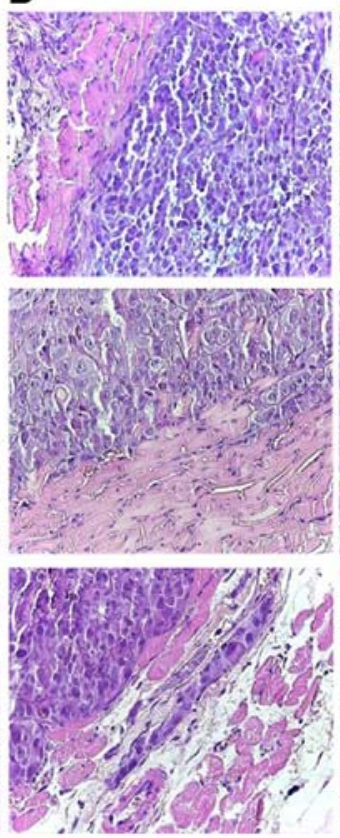

C
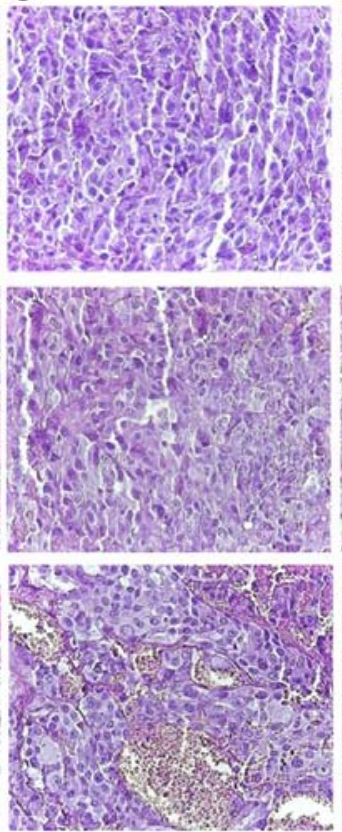

D
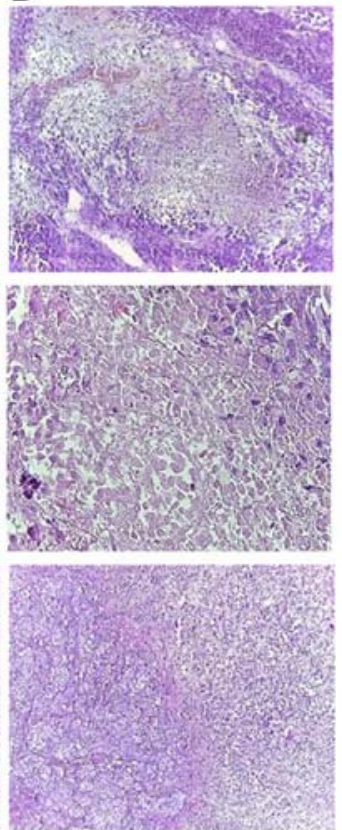

Figure 6. Microscopic features of primary skin tumors during the experiment, H\&E staining. (A) Nodular tumor occupying the entire dermis, extending to the subcutis, but with grenz zone to the epidermis (original magnification, $\mathrm{x} 40$ ). (B) Tumor cells invading striated muscle cells (original magnification, $\mathrm{x} 400$ ). (C) Achromic epithelioid malignant melanocytes with vesiculous nuclei and eosinophilic macronucleoli (original magnification, x400). (D) Area of necrosis (original magnification, $\mathrm{x} 40$ ).

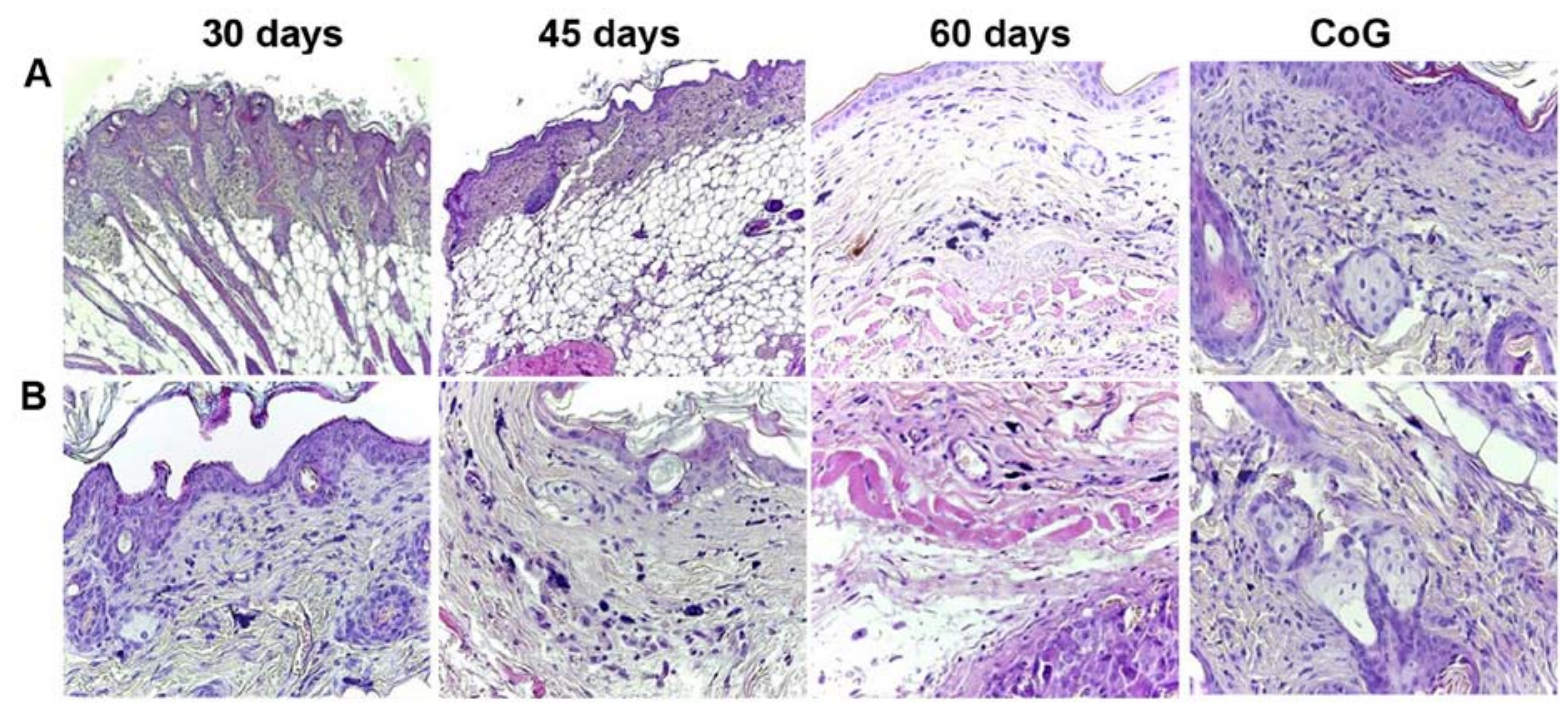

Figure 7. Specimens of the skin (A) surrounding and (B) around the tumor: the number of mast cells increased from the control group to the mice sacrificed at 60 days after inoculation, and the distribution of mast cells varied from the superficial dermis in the first group ( 30 days) to the deep dermis and subcutis in the last group (60 days), H\&E staining. CoG, control group.

through the RAS-RAF-MEK-ERK-MAP kinase signaling pathway. The $B-R A F$ mutation is represented by the substitution of valine with glutamic acid at codon 600 , also known as $\mathrm{V} 600 \mathrm{E}$, and is responsible for the constitutive activation of the protein $(30,31)$. Moreover, it has been demonstrated that the $B-R A F^{V 600 E}$ pathway promotes vascular development by activating the autocrine secretion of VEGF (31). Mutations in the $B-R A F$ gene have been diagnosed in up to $82 \%$ melanocytic nevi, concluding that $B-R A F^{V 600}$ mutation cannot lead to cancer itself, and requires the presence of other mutated genes (32). Another study on B16 mouse melanomas, demonstrated that the inhibition of $M I T F$ reduces the proliferation of malignant melanocytes (28). Therefore, it can be concluded that MITF and $B-R A F$ activation are necessary for melanocytes to acquire their malignant potential (28).

In the present study, we used the A375 melanoma cell line that maintains the characteristics of the human genitor and harbors $B-R A F$ and $C D K N 2$ mutations, typical of cutaneous 


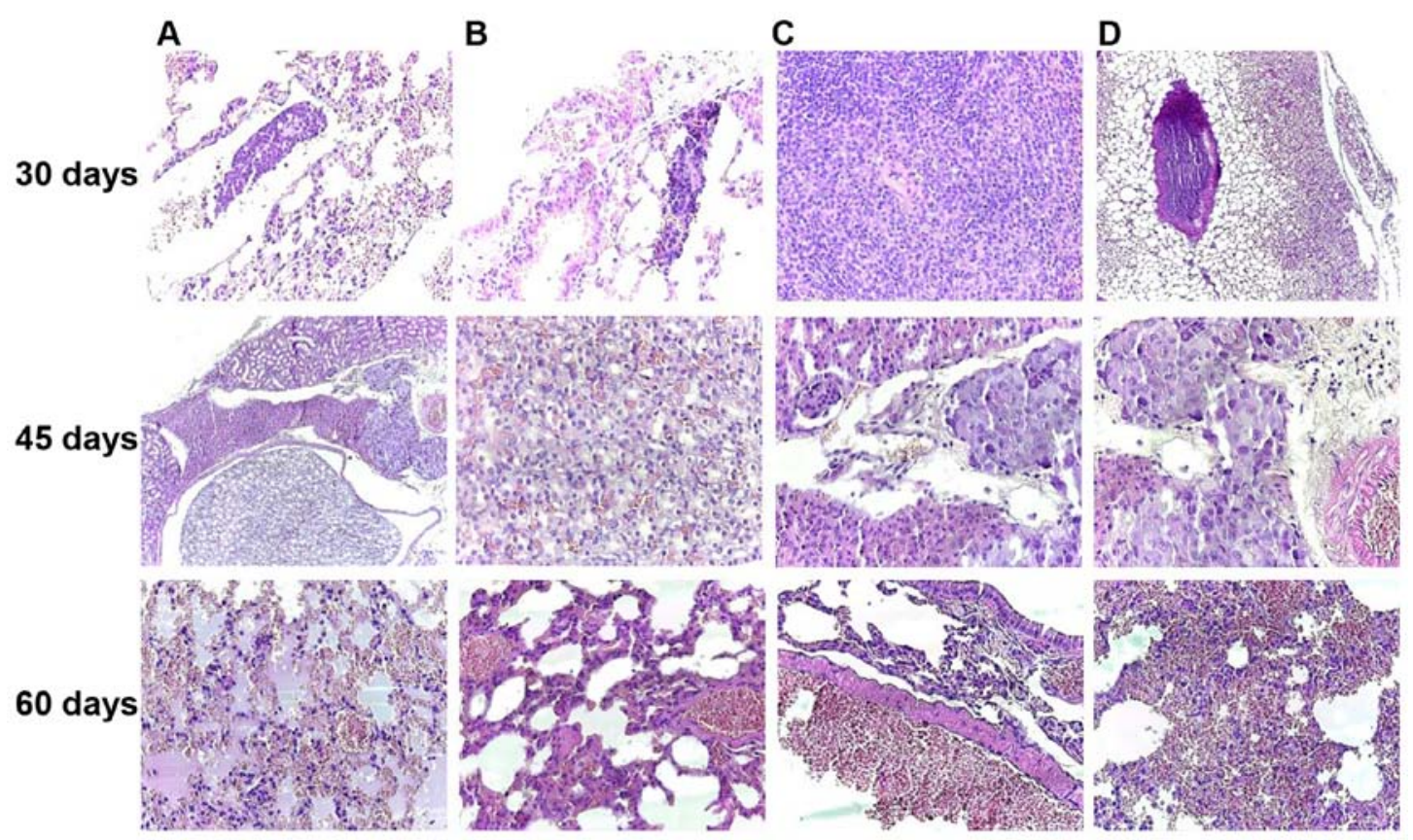

Figure 8. Melanoma achromic metastasis at 30 days post-inoculation in the lung ( $\mathrm{A}$ and $\mathrm{B}$, original magnification, $\mathrm{x} 40$ ) and spleen (C, original magnification, x100) and tumor thrombus in the big arterial blood vessel (D, original magnification, x40); Kidney metastases was noted in the 45th day after inoculation, disposed between the renal tubules and nearby medium-sized arterial vessels of the renal medulla (A, original magnification, x40) and composed of achromic epithelioid cells similar to those observed in the primary tumor (B, original magnification, x100; C and D, original magnification, $\mathrm{x} 40$ ); On the 60 th day of the experiment, the most affected internal organ was the lung, with hemorrhagic alveolitis (A, original magnification, $\mathrm{x} 40$ ), hyperemia of small- and medium-sized blood vessels (B and C, original magnification, x100) and many extravasated erythrocytes in the alveolar spaces (D, original magnification, x40), H\&E staining.

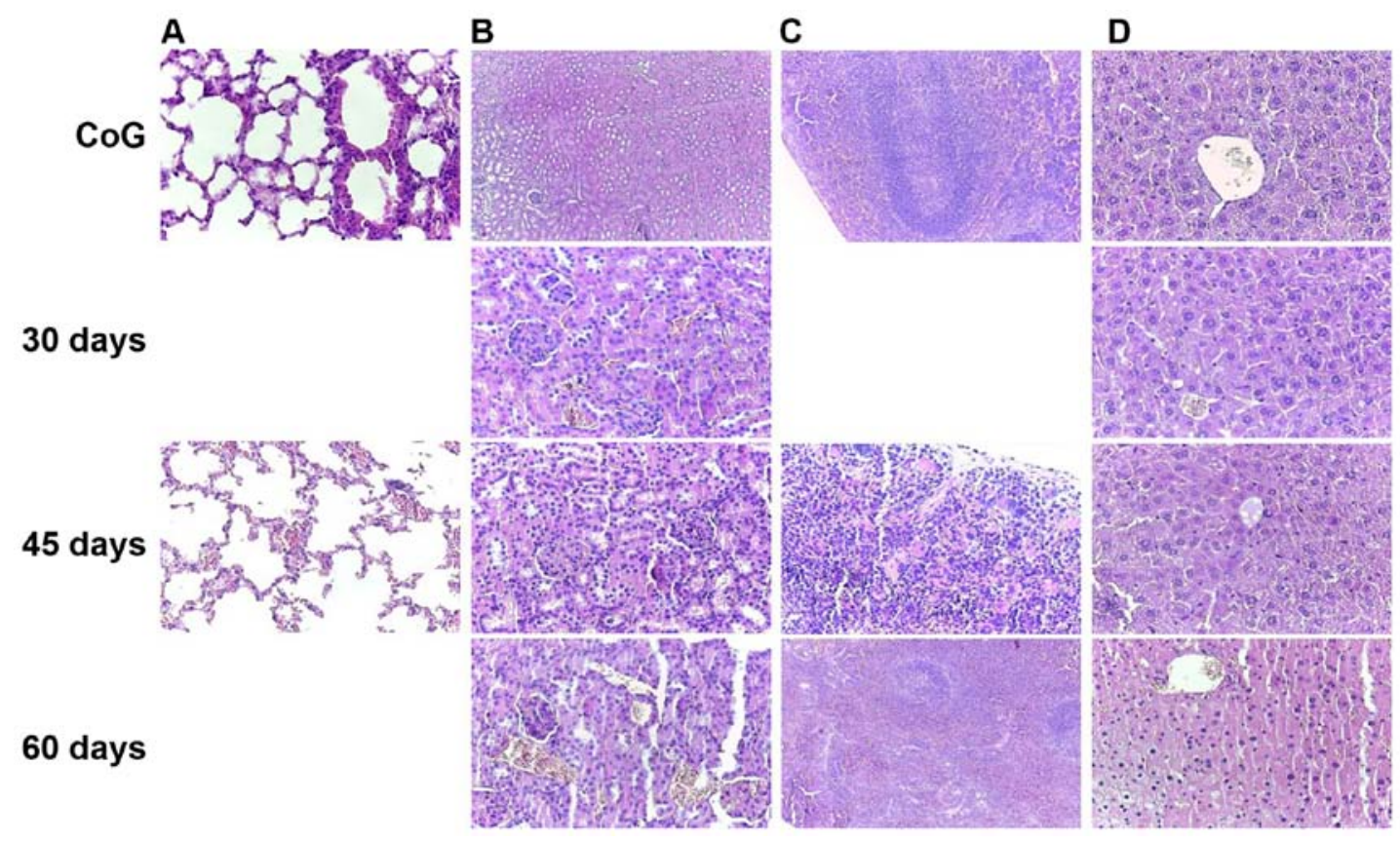

Figure 9. Histopathological aspects of the internal organs non-affected by metastasis showed hyperemia of (A) interalveolar capillaries and small arteries, hyperemia of (B) kidney peritubular and glomerular capillaries, hyperemia of (C) splenic sinusoids, and hyperemia of (D) hepatic centrilobular venules, compared to the normal aspects noted in the control group, with increasing intensity from mild at 30 days post-inoculation, to moderate at 45 days and intense at 60 days post-inoculation, H\&E staining. CoG, control group.

melanoma, but with a morphology similar to that of mucosal melanomas. Even so, it represents an eligible candidate for the development of in vivo models.
It is well-known that melanoma progression occurs in several steps which include the formation of a primary tumor that develops horizontally through the epidermis, followed by 
the vertical growth phase initiated in the primary tumor that extends to dermis and the last phase, the invasion of tumor cells and formation of secondary tumors (33). Metastasis is a complex multi-stage process and a lethal feature of melanoma, causing also resistance to the existent treatment. The process of angiogenesis is a prominent feature in melanoma development, progression and metastasis, the newly formed vessels being the suppliers of oxygen and nutrients for cancer cells. Moreover, it is considered that the onset of angiogenesis is related to inflammation and the development of the melanoma vertical growth phase $(33,34)$. On this basis, it is mandatory to develop proper in vitro and in vivo models that mimic the human pathogenesis concerning metastasis development, in order to fully elucidate the processes involved (35). However, even though multiple models have been employed, these processes are not yet fully elucidated.

The in vivo model using melanoma cells grafted on chick chorioallantoic membrane presented in this study demonstrated a $100 \%$ rate of tumor formation, and it could be applied as a pre-screening tool for the evaluation of the antitumor and antiangiogenic potential of various agents, the results being obtained in a short period of time (4-8 days). The easily accessible, highly vascularized extraembryonic membrane of the chicken embryo is often used to assess tumor angiogenesis, since the discovery of tumor angiogenesis by Folkman and Cotran 4 decades ago (36). Several advantages of this technique recommend it as a pre-screening assay to the murine models. The procedure assets are in terms of costs, time, simplicity and reproducibility. The model does not require sophisticated technical equipment, and qualified surgical skills are not compulsory. The experimental setting takes up to 17 days, which implies a relatively short interval for tumor growth and metastasis, thus facilitating multiple assessments. Human tumor xenografts are applicable on the CAM surface due to immunological immaturity up to embryonic development day 18 (37,38). Moreover, the number of specimens that can be included in an experimental set is higher than in mouse studies, making it possible to investigate a greater number of therapeutic agents.

Another feature that can be investigated by assessing the melanoma CAM assay is the degree of angiogenesis by morphometric measurements, applying an arbitrary scale in correlation to the vessel density in areas surrounding the tumors. By performing this evaluation on the 4th day following the inoculation of cells, or the cell medium, respectively, there is no interference with the normal angiogenic status of the embryo. This moment represents the 14th EDD, when the normal angiogenic process of untreated specimens is normally already decreased. Intense angiogenesis occurs between the 7th and 11th EDD (22). Our results indicated that on day 4 post-inoculation, both primary and distant tumors were strongly vascularized, what indicates the bond between the tumor growth and angiogenesis.

Wehave previously used the CAM normal angiogenesis model to test certain natural compounds for their potential benefits in limiting the deregulated excessive angiogenic process $(39,40)$. We have also previously tested the natural compounds in the melanoma model on CAM using A375 cells, providing new insight into the mechanisms of action (unpublished data).

Different melanoma cell lines have been used for models using the CAM assay, with the A375 cells being among the most frequently used $(16,41)$. This has contributed to the molecular elucidation of this aggressive type of tumor behavior, in terms of invasiveness (16), brain metastasis (42), angiogenesis and lymphangiogenesis $(41,42)$, or the evaluation of compounds with promising effects by modulating different targets (43).

The human melanoma model using A375 cells assessed on the CAM is also a useful alternative method for the study of melanoma cell behavior and tumor environment. The CAM protocol using melanoma cells is a suitable tool for in vivo tumor angiogenesis or lymphangiogenesis elucidations. Hence, further molecular investigations can be performed using the specimens obtained from the tumor CAM assay [e.g., polymerase chain reaction (PCR), in situ hybridization, immunohistochemistry, immunofluorescence, and positron emission tomographycomputed tomography (PET-CT)] (38). The establishment of functional perfused tumors in only 4 days after inoculation and the ability of observing the tumor growth, progress, invasiveness and metastasis for approximately 4-5 days after tumor onset is a suitable protocol for pre-screening potential antitumor agents.

There are several drawbacks to the CAM model that can influence tumor research results. A limited number of reagents are applicable due to low compatibility. Non-specific inflammatory response, and various reactions of the membrane when exposed to the outer atmosphere can also affect tumor microenvironment assessment (44). In order to minimize the possible misevaluations of the tumor model, it is optimal to apply both the murine and CAM assays along with in vitro experiments.

The CAM data obtained in the present study validate the effectiveness of this assay as a short-term xenograft model for A375 cells, providing information about melanoma cell proliferation, metastatic behavior and angiogenic potential in vivo. This information was used as an additional background file for the development of human melanoma mouse model (a long-term assay).

The mouse melanoma model can be used to gain information about both early-and late-stage events in melanoma development, and furthermore, the antitumor and anti-metastatic effects of various therapeutic agents can be assessed. In order to obtain a proper mouse melanoma model, several aspects should be noted:

First, the in vivo melanoma models which are obtained by the engraftment of humancells require as hostimmunocompromised mice (SCID mice, which are both T-cell- and B-cell-deficient or nude mice, which are only T-cell-deficient) that do not reject the inoculated cells $(3,45)$. An ideal animal model should exhibit similar molecular characteristics as human tumorigenesis and should also mimic natural tumor progression, from its burst and proliferation to invasion and metastasis (3). Balb/c nude mice have been proven to be an excellent host for the A375 mouse model (46-49). Immunodeficient mice are considered eligible hosts for the transplantation of human xenografts due to their specific mutations and immune background. SCID mice were the first severe immunocompromised strain of mice that presented a mutation at Prkdc ${ }^{\text {scid }}$ protein kinase, also known as Scid mutation responsible for the impairment of B- and T-cell production (50). Balb/c homozygote nude mice are characterized by the mutation of the Foxnl gene associated with the lack of hair and of a functional thymus (deteriorated of removed). The immune profile of these mice comprises 
a small population of T-cells and an increased response of natural killer cells (more potent that in normal Balb/c mice), which makes them suitable for human xenografts. It has been observed that with age, the athymic mice gather a small number of lymphocytes (CD3, CD4, CD8 and Thy-1). In addition, it has been shown that these mice do not have an intrinsic defect of T-cell precursors, their function being activated with proper stimulation; however, B-lymphocytes, mononuclear cells (macrophages highly active) and a normal number of mast cells have also been detected $(50,51)$.

Second, the area of xenograft inoculation is very important, as it should provide the anatomical morphology for tumor progression and the development of metastases. Most of the xenograft melanoma models are created by the subcutaneously inoculation of tumor cells, with the number and the volume of culture media/PBS/inoculum varying (47-49). Alternative parenteral pathways of tumor cell inoculation have also been described, such as intradermal (better mimics a primary melanoma, but tumor formation leads to skin ulcerations and mouse euthanasia is required) $(35,45,46)$, tail vein (enforces the development of lung metastasis, but some steps in the normal process are missed) $(3,45)$ and intracardiac (follows the metastatic spread) (52).

The xenograft melanoma model subcutaneously inoculated presents some advantages in that the tumor that develops is more comparable to skin metastasis and the experimental time is longer, allowing for human melanoma cells to interact with the murine stroma, lymphatic vessels, which makes the evaluation of tumor growth behavior possible; this is frequently used to evaluate the response of anticancer agents response in vivo $(3,45)$. However, there are also some limitations to this model, in that the tumor dimensions cannot be measured by a caliper at lower limits and it cannot be applied to examine the efficacy of immune-based therapies, since the mice are immunocompromised (53).

Our results are in agreement with the data from the literature regarding the inoculation pathway $(23,47-49)$, the animal host and the number of cells/inoculum/mice $(23,49)$, this number being selected based on the fact that a palpable subcutaneous tumor was first detected after the injection of a minimum of $10^{6}$ cells/mouse (54). There were some differences between our data and the literature as regards the survival time post-inoculation of the tumor cells (from 21 to 90 days); these differences could be explained by the inoculation pathway, the number of cells/inoculum and also, the aim and the endpoints established for each experimental design (34,47-49).

As regards histopathological aspects, cutaneous melanomas can be classified as melanomas in situ, superficial spreading melanomas and nodular melanomas. Extra-cutaneous melanoma do not fit these categories due to zone particularities; mucosal melanomas are often diagnosed as nodular tumors with or without associated pagetoid spread in the covering epithelium nearby the melanoma. In our study, 14 mice developed tumors consistent with the diagnosis of nodular melanoma that occupied the dermis and subcutis. The cells composing melanoma can be classified as epithelioid and spindle, although the majority of cutaneous melanomas present a mixed cellularity, with epithelioid cells being more often observed in mucosal melanomas (2). In the present study, we used the A375 cell line, containing cells with epithelioid aspect obtained from a cutaneous lesion, and the induced tumors were all composed of epithelioid cells, better resembling mucosal melanoma cellularity. Moreover, even if, usually, cutaneous melanomas are pigmented, containing various amounts of melanin in the cytoplasm of tumor cells or in the melanophages of the tumor stroma, the tumors obtained in the present study were achromic, better resembling mucosal melanomas that are predominantly achromic. As we have already demonstrated, the tumor cells present a pagetoid spread in the epithelium nearby or overlying the tumor $(1,2)$, a feature that was not observed in the present study, certainly due to the subcutaneous inoculation of the tumor cells; however, the tumor occupied the dermis and the subcutis, providing the tumor with direct access to the usual routes for metastasis, which resulted in the appearance of secondary tumors in almost $30 \%$ of the xenografted mice.

The evolution of both cutaneous and extra-cutaneous melanomas is dependent on the stage of disease at diagnosis. In a recent review, it was stated that in countries with the highest incidence of cutaneous melanoma, such as Australia, New Zealand, USA and Scandinavia, patients are diagnosed at an early stage, while in Central and Eastern European countries, diagnosis is usually made at an advanced stage, which leads to a higher number of deaths due to melanoma (55). It is well-known that cutaneous melanomas diagnosed at an early stage are in most cases curable, whereas the survival rate changes depending on the stage of the disease: stages I and II (localized tumor; 5-year survival, 98\% of cases); stage III (regional spread; $63 \%$ of cases) and stage IV melanoma (metastasis beyond regional lymph nodes; $16 \%$ of cases) (25). Mucosal melanomas are always diagnosed in the late stages, with very low rates of curability. The prognosis is grim, the 5-year survival rate being only $40 \%$.

The prognostic factors have been investigated for a number of years. From the beginning of the study of melanoma to date, the Clark level (the level of the skin affected by the tumor with level I, epidermis; level II, papillary dermis; level III, superficial blood plexus of the dermis; level IV, profound blood plexus of the dermis; and level V, subcutis) and the Breslow index (distance in $\mathrm{mm}$ from the granular layer of the epidermis to the most profound site of the tumor) are considered to be the most important for the prognostic. The epithelioid appearance of the cells was also noted as poor prognostic factor, together with the lack of melanin pigment from the cells (2). The quantity of inflammatory cells (lymphocytes, macrophages and plasma cells), varying from any (poor prognostic factor), to brisk, or to heavy and disposed in a band around the tumor (good prognostic feature), was also considered to have an impact on the prognosis of the tumor. Lately, only infiltrated plasma cells, those plasma cells that are found between malignant melanocytes, are considered important for a good prognosis, with no impact on survival if they are disposed in the tissues around the tumor. To date, only the Clark level and Breslow index remain as gold standards for prognosis, and are the only factors that could be appreciated in our study and could be associated with prognosis, as tumor size rapidly increased and reached the limits imposed for mouse euthanasia by the IACUC Guidelines regarding tumor production in rats and mice, as many metastases developed. At 30 days post-inoculation, the primary tumors of 3 mice reached the size limits and all these 
mice developed distance metastasis or showed signs of tumor migration (tumor thrombus in the large-sized arterial blood vessel). Maishi et al reported that on day 29 post-inoculation of $1 \times 10^{6}$ cells into Balb/c nude mice, lung metastases and tumor cells disseminated in intra-blood vessels areas were detected (48), data that are consistent with our results.

In the second group (45 days post-inoculation), only one mouse developed a microscopic kidney metastasis and in the last group (60 days post-inoculation), the mice in which the tumor size slowly reach the limit showed no metastasis, only non-specific signs of tumor aggression as paraneoplastic symptoms (hemorrhagic alveolitis). As regards the epithelioid feature and intracytoplasmic melanin load, in the present study, the inoculated A375 cells had an achromic epithelioid aspect and all the primary and secondary tumors developed after inoculation were also composed by achromic epithelioid cells; thus, no remarks related to the differences in metastatic capacity between epithelioid and spindle cells, or pigmented and achromic cells, could be pronounced. Moreover, inflammatory cells were absent in the tumor and metastasis obtained using $\mathrm{Balb} / \mathrm{c}$ nude mice, due to the immune system characteristics of the used mice. As we previously demonstrated (56) in SKH-1 hairless mice while studying experimental skin carcinogenesis, the only type of inflammatory cells present in the tissues around the tumor were mast cells. These cells were easy to observe even on morphologic H\&E or trichrome stains, due to their microscopic appearance, as large cells with a thin cytoplasmic extension, that are usually filled with many rough basophilic granules. The present mouse model exhibited an increase in the number and size of mast cells from the control group to the mice sacrificed after 60 days of the experiment. From the facts noted in the present study, it can be concluded that the size of the tumor has an important impact on the appearance of metastasis. Due to the increasing number of mast cells around the tumor, it can be postulated that the immune system is probably involved in the evolution, progression and metastasis of the tumor. Of note, the host immune system is considered to be involved in tumor regression as a consequence of tumor cell destruction by the activation of inflammatory cells, vascular hyperplasia and fibrosis (27).

Even so, no other histological features noted on the primary tumor in the present study, could predict metastasis, the presence of metastases being a random event, an aspect already highlighted in humans, where it seems that the behavior of different melanomas does not correlate with the surgical option or histopathological type of the tumor cells.

In conclusion, the CAM assay indicated that the A375 cell line exhibited a great affinity and compatibility in the present framework, primary and secondary tumors being visible at day 4 post-inoculation and presenting a high angiogenic potential. The in vivo melanoma model obtained by inoculating A375 cells revealed that Balb/c nude mice are suitable hosts for human cancers, the degree of tumor development with similar characteristics being greater than $90 \%$. Moreover, the histological analysis described tumor evolution in time, its progress being slow and its metastasis rate reduced, which can be considered an asset in therapeutic surveillance experiments. The standardization method for the development of melanoma models proposed in the present study proved to be a complex, reproducible process, albeit some small interferences, and the incriminated factor could be the genetic profile of both cell line and nude mice.

\section{Acknowledgements}

The present study was supported by an Internal grant at 'Victor Babeș' University of Medicine and Pharmacy Timisoara (PII-C2-TC-2014, CAMMelRasNa), obtained by Avram Stefana. This study was financially supported by a grant from the Romanian National Authority for Scientific Research and Innovation, CNCS-UEFISCDI, project no. PN-II-RU-TE-2014-4-2842. The authors would like to thank the Histology and Angiogenesis Department for providing technical support and assistance in setting up the CAM assay.

\section{References}

1. Baderca F, Cojocaru S, Lazăr E, Lăzureanu C, Lighezan R, Alexa A, Raica M and Nicola T: Amelanotic vulvar melanoma: Case report and review of the literature. Rom J Morphol Embryol 49: 219-228, 2008.

2. Baderca F, Vincze D, Balica N and Solovan C: Mucosal melanomas in the elderly: Challenging cases and review of the literature. Clin Interv Aging 9: 929-937, 2014.

3. Kuzu OF, Nguyen FD, Noory MA and Sharma A: Current State of Animal (Mouse) Modeling in Melanoma Research. Cancer Growth Metastasis 8 (Suppl 1): 81-94, 2015.

4. Potrony M, Badenas C, Aguilera P, Puig-Butille JA, Carrera C, Malvehy $\mathbf{J}$ and Puig S: Update in genetic susceptibility in melanoma. Ann Transl Med 3: 210, 2015.

5. Delyon J, Varna M, Feugeas JP, Sadoux A, Yahiaoui S, Podgorniak MP, Leclert G, Dorval SM, Dumaz N, Janin A, et al: Validation of a preclinical model for assessment of drug efficacy in melanoma. Oncotarget 7: 13069-13081, 2016.

6. Candido S, Rapisarda V, Marconi A, Malaponte G, Bevelacqua V, Gangemi P, Scalisi A, McCubrey JA, Maestro R, Spandidos DA, et al: Analysis of the $B-R a f^{V 600 \mathrm{E}}$ mutation in cutaneous melanoma patients with occupational sun exposure. Oncol Rep 31: 1079-1082, 2014.

7. Palmieri G, Colombino M, Sini MC, Ascierto PA, Lissia A and Cossu A: Targeted Therapies in Melanoma: Successes and Pitfalls. In: Melanoma-From Early Detection to Treatment. Duc GHT (ed). InTech Open, Reykjavik, pp29-58, 2013.

8. Sun C, Wang L, Huang S, Heynen GJ, Prahallad A, Robert C, Haanen J, Blank C, Wesseling J, Willems SM, et al: Reversible and adaptive resistance to $\mathrm{BRAF}(\mathrm{V} 600 \mathrm{E})$ inhibition in melanoma. Nature 508: 118-122, 2014

9. Russo A, Ficili B, Candido S, Pezzino FM, Guarneri C, Biondi A, Travali S, McCubrey JA, Spandidos DA and Libra M: Emerging targeted therapies for melanoma treatment (review). Int J Oncol 45: 516-524, 2014.

10. Chalkiadaki G, Nikitovic D, Katonis P, Berdiaki A, Tsatsakis A, Kotsikogianni I, Karamanos NK and Tzanakakis GN: Low molecular weight heparin inhibits melanoma cell adhesion and migration through a $\mathrm{PKCa} / \mathrm{JNK}$ signaling pathway inducing actin cytoskeleton changes. Cancer Lett 312: 235-244, 2011.

11. Yamanaka K, Nakahara T, Yamauchi T, Kita A, Takeuchi M, Kiyonaga F, Kaneko N and Sasamata M: Antitumor activity of YM155, a selective small-molecule survivin suppressant, alone and in combination with docetaxel in human malignant melanoma models. Clin Cancer Res 17: 5423-5431, 2011.

12. Ribatti D: The CAM assay in the study of angiogenesis and metastasis. In: The Chick Embryo Chorioallantoic Membrane in the Study of Angiogenesis and Metastasis, Springer Netherlands, 2010.

13. Murphy JB and Rous P: The behavior of chicken sarcoma implanted in the developing embryo. J Exp Med 15: 119-132, 1912.

14. Deryugina EI and Quigley JP: Chick embryo chorioallantoic membrane model systems to study and visualize human tumor cell metastasis. Histochem Cell Biol 130: 1119-1130, 2008.

15. Klingenberg M, Becker J, Eberth S, Kube D and Wilting J: The chick chorioallantoic membrane as an in vivo xenograft model for Burkitt lymphoma. BMC Cancer 14: 339, 2014. 
16. Ribatti D, Nico B, Cimpean AM, Raica M, Crivellato E, Ruggieri S and Vacca A: B16-F10 melanoma cells contribute to the new formation of blood vessels in the chick embryo chorioallantoic membrane through vasculogenic mimicry. Clin Exp Med 13: 143-147, 2013.

17. LiM,PathakRR,Lopez-RiveraE,Friedman SL,Aguirre-GhisoJA and Sikora AG: The In Ovo Chick Chorioallantoic Membrane (CAM) Assay as an Efficient Xenograft Model of Hepatocellular Carcinoma. J Vis Exp 2015: e52411-e52411, 2015.

18. Comşa Ş, Popescu R, Avram Ş, Ceaușu RA, Cîmpean AM and Raica M: Bevacizumab Modulation of the Interaction Between the MCF-7 Cell Line and the Chick Embryo Chorioallantoic Membrane. In Vivo 31: 199-203, 2017.

19. Workman P, Aboagye EO, Balkwill F, Balmain A, Bruder G, Chaplin DJ, Double JA, Everitt J, Farningham DA, Glennie MJ, et al; Committee of the National Cancer Research Institute: Guidelines for the welfare and use of animals in cancer research. Br J Cancer 102: 1555-1577, 2010.

20. Ha L, Noonan FP, De Fabo EC and Merlino G: Animal models of melanoma. J Investig Dermatol Symp Proc 10: 86-88, 2005.

21. Becker JC, Houben R, Schrama D, Voigt H, Ugurel S and Reisfeld RA: Mouse models for melanoma: A personal perspective. Exp Dermatol 19: 157-164, 2010.

22. Ribatti D: The chick embryo chorioallantoic membrane in the study of tumor angiogenesis. Rom J Morphol Embryol 49: $131-135,2008$

23. Mena S, Rodriguez ML, Ortega A, Priego S, Obrador E, Asensi M, Petschen I, Cerdá M, Brown BD and Estrela JM: Glutathione and Bcl-2 targeting facilitates elimination by chemoradiotherapy of human A375 melanoma xenografts overexpressing bcl-xl, bcl-2, and mcl-1. J Transl Med 10: 8, 2012.

24. Rigon RB, Oyafuso MH, Fujimura AT, Gonçalez ML, do Prado AH, Gremião MP and Chorilli M: Nanotechnology-Based Drug Delivery Systems for Melanoma Antitumoral Therapy: A Review. BioMed Res Int 2015: 841817, 2015.

25. Niezgoda A, Niezgoda P and Czajkowski R: Novel Approaches to Treatment of Advanced Melanoma: A Review on Targeted Therapy and Immunotherapy. BioMed Res Int 2015: 851387, 2015.

26. Baderca F, Solovan C and Boghian L: Epidemiological and morphological data of ocular melanocytic lesions. Rom J Morphol Embryol 54: 77-83, 2013.

27. Zurac S, Neagu M, Constantin C, Cioplea M, Nedelcu R, Bastian A, Popp C, Nichita L, Andrei R, Tebeica T, et al: Variations in the expression of TIMP1, TIMP2 and TIMP3 in cutaneous melanoma with regression and their possible function as prognostic predictors. Oncol Lett 11: 3354-3360, 2016.

28. Wang L, Hurley DG, Watkins W, Araki H, Tamada Y, Muthukaruppan A, Ranjard L, Derkac E, Imoto S, Miyano S, et al: Cell cycle gene networks are associated with melanoma prognosis. PLoS One 7: e34247, 2012

29. Fedorenko IV, Gibney GT and Smalley KSM: NRAS mutant melanoma: Biological behavior and future strategies for therapeutic management. Oncogene 32: 3009-3018, 2013

30. Rodrigueza WV, Woolliscroft MJ, Ebrahim AS, Forgey R, McGovren PJ, Endert G, Wagner A, Holewa D, Aboukameel A, Gill RD, et al: Development and antitumor activity of a BCL-2 targeted single-stranded DNA oligonucleotide. Cancer Chemother Pharmacol 74: 151-166, 2014.

31. Russo AE, Torrisi E, Bevelacqua Y, Perrotta R, Libra M McCubrey JA, Spandidos DA, Stivala F and Malaponte G: Melanoma: Molecular pathogenesis and emerging target therapies (Review). Int J Oncol 34: 1481-1489, 2009.

32. Jones V and Katiyar SK: Emerging phytochemicals for prevention of melanoma invasion. Cancer Lett 335: 251-258, 2013.

33. Ribatti D, Annese T and Longo V: Angiogenesis and melanoma. Cancers (Basel) 2: 114-132, 2010.

34. Streit $\mathrm{M}$ and Detmar M: Angiogenesis, lymphangiogenesis, and melanoma metastasis. Oncogene 22: 3172-3179, 2003.

35. Rozenberg GI, Monahan KB, Torrice C, Bear JE and Sharpless NE: Metastasis in an orthotopic murine model of melanoma is independent of RAS/RAF mutation. Melanoma Res 20: 361-371, 2010

36. Folkman $\mathbf{J}$ and Cotran R: Relation of vascular proliferation to tumor growth. Int Rev Exp Pathol 16: 207-248, 1976.

37. Friend JV, Crevel RW, Williams TC and Parish WE: Immaturity of the inflammatory response of the chick chorioallantoic membrane. Toxicol In Vitro 4: 324-326, 1990.
38. Dupertuis YM, Delie F, Cohen M and Pichard C: In ovo method for evaluating the effect of nutritional therapies on tumor development, growth and vascularization. Clin Nutr Exp 2: 9-17, 2015.

39. Dehelean CA, Feflea S, Ganta S and Amiji M: Anti-angiogenic effects of betulinic acid administered in nanoemulsion formulation using chorioallantoic membrane assay. J Biomed Nanotechnol 7: 317-324, 2011

40. Dehelean CA, Feflea S, Gheorgheosu D, Ganta S, Cimpean AM, Muntean D and Amiji MM: Anti-angiogenic and anti-cancer evaluation of betulin nanoemulsion in chicken chorioallantoic membrane and skin carcinoma in Balb/c mice. J Biomed Nanotechnol 9: 577-589, 2013.

41. Papoutsi M, Siemeister G, Weindel K, Tomarev SI, Kurz H, Schächtele C, Martiny-Baron G, Christ B, Marmé D and Wilting J: Active interaction of human A375 melanoma cells with the lymphatics in vivo. Histochem Cell Biol 114: 373-385, 2000.

42. Papoutsi M, Kurz H, Schächtele C, Marmé D, Christ B, Pröls F and Wilting J: Induction of the blood-brain barrier marker neurothelin/HT7 in endothelial cells by a variety of tumors in chick embryos. Histochem Cell Biol 113: 105-113, 2000.

43. Marton A, Kúsz E, Kolozsi C, Tubak V, Zagotto G, Buzás K, Quintieri L and Vizler C: Vanillin Analogues o-Vanillin and 2,4,6-Trihydroxybenzaldehyde Inhibit NFkB Activation and Suppress Growth of A375 Human Melanoma. Anticancer Res 36: 5743-5750, 2016

44. Nowak-Sliwinska P, Segura T and Iruela-Arispe ML: The chicken chorioallantoic membrane model in biology, medicine and bioengineering. Angiogenesis 17: 779-804, 2014

45. Beaumont KA, Mohana-Kumaran N and Haass NK: Modeling Melanoma In Vitro and In Vivo. Healthcare (Basel) 2: 27-46, 2013.

46. Hu T, Zhang C, Tang Q, Su Y, Li B, Chen L, Zhang Z, Cai T and Zhu Y: Variant G6PD levels promote tumor cell proliferation or apoptosis via the STAT3/5 pathway in the human melanoma xenograft mouse model. BMC Cancer 13: 251, 2013.

47. Zheng AW, Jia DD, Xia LM, Jin G, Wu H and Li T: Impact of carboplatin plus paclitaxel combined with endostar against A375 melanoma cells: An in vitro and in vivo analysis. Biomed Pharmacother 83: 1321-1326, 2016.

48. Maishi N, Ohba Y, Akiyama K, Ohga N, Hamada J, Nagao-Kitamoto H, Alam MT, Yamamoto K, Kawamoto T, Inoue $\mathrm{N}$, et al: Tumour endothelial cells in high metastatic tumours promote metastasis via epigenetic dysregulation of biglycan. Sci Rep 6: 28039, 2016.

49. Jin J, Zhang Y, Li Y, Zhang H, Li H, Yuan X, Li X, Zhou W, $\mathrm{Xu} \mathrm{B}$, Zhang $\mathrm{C}$, et al: RNA-interference-mediated downregulation of Pin1 suppresses tumorigenicity of malignant melanoma A375 cells. Neoplasma 60: 92-100, 2013.

50. Belizario JE: Immunodeficient Mouse Models: An Overview. Open Immunol J 2: 79-85, 2009.

51. Envigo: Research Models and Services: Oncology-Mutant Mice. Athymic Nude Mice. Envigo RMS Division, Indianapolis, IN 2016. http://www.envigo.com/resources/data-sheets/envigo-5193 -131-leaflets-2016-nude-mouse-combination-a4-refs.pdf.

52. Herwig N, Belter B and Pietzsch J: Extracellular S100A4 affects endothelial cell integrity and stimulates transmigration of A375 melanoma cells. Biochem Biophys Res Commun 477: 963-969, 2016.

53. Clark AG and Vignjevic DM: Modes of cancer cell invasion and the role of the microenvironment. Curr Opin Cell Biol 36: 13-22, 2015.

54. Craft N, Bruhn KW, Nguyen BD, Prins R, Liau LM, Collisson EA, De A, Kolodney MS, Gambhir SS and Miller JF: Bioluminescent imaging of melanoma in live mice. J Invest Dermatol 125: $159-165,2005$.

55. Gajda M and Kaminska-Winciorek G: Do not let to be late: Overview of reasons for melanoma delayed diagnosis. Asian Pac J Cancer Prev 15: 3873-3877, 2014.

56. Dehelean CA, Soica C, Pinzaru I, Coricovac D, Danciu C, Pavel I, Borcan F, Spandidos DA, Tsatsakis AM and Baderca F: Sex differences and pathology status correlated to the toxicity of some common carcinogens in experimental skin carcinoma. Food Chem Toxicol 95: 149-158, 2016 